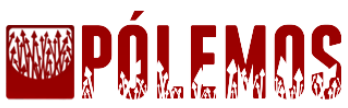

\section{KANT E O COMÉRCIO PSICO-FÍSICO}

\author{
O influxo entre corpo e alma
}

\author{
Márcio Tadeu Girotti \\ Doutorando em Filosofia pela Universidade Federal de São Carlos - UFSCar
}

\begin{abstract}
RESUMO
Diante da crítica kantiana lançada às concepções metafísicas sobre a doutrina da alma, buscaremos abordar a questão do comércio psico-físico (troca de informações), entre o mundo sensível e suprassensível, ou, entre a alma, o corpo e o espírito. A problemática do comércio psico-físico é tratada por Kant na obra Sonhos de um visionário explicados por sonhos da metafísica (1766), por conta da figura de Swedenborg, um entusiasta do mundo suprassensível, um visionário sueco, que afirma ter contato com o mundo dos espíritos. Com isso, Kant aborda a definição do conceito de espírito, bem como o problema da relação alma e corpo, dentro da questão da impenetrabilidade: como pode um ser imaterial ocupar um ser material? Na Dissertação de 1770, Kant retoma a questão acerca das relações que se estabelecem entre corpos físicos e entre tais corpos e uma possível unidade do Mundo encontrada em um ser fora do mundo, ou uma causa comum (única): Deus. Essas relações, em certo sentido, fazem referência ao comércio psico-físico estabelecido nos Sonhos de um visionário. Já na Crítica da razão pura (1787), a questão é retomada com referência à crítica de Kant às teorias tradicionais da doutrina pura da alma, que não são senão "paralogismos da doutrina transcendental da alma, a qual é tomada falsamente como ciência da razão pura sobre a natureza do ente pensante" $(\mathrm{KrV}$, B 403). Nesse sentido, trataremos a questão entre as três obras citadas, buscando, ao menos, levantar a questão da possibilidade da comunicação entre um mundo e outro e, talvez, entre um ser e o outro.
\end{abstract}

Palavras-chave: Influxo psico-físico; Alma e corpo; Swedenborg.

\section{ABSTRACT}

Facing up Kantian criticism raised to metaphysical conceptions on soul doctrine, we will seek an account psycho-physical commerce question (information exchange), between supersensible and sensitive world, or, between soul, body and spirit. The psycho-physical commerce problematic is treated by Kant in Dreams of a Spirit-Seer Elucidated by Dreams of Metaphysics (1766), in reason of Swedenborg, an enthusiastic of supersensible world, a Swedish visionary, which asserts has contact with the world of spirits. Therefore, Kant approaches the spirit concept definition, as the soul/body problem, into the impenetrability question: how an immaterial being occupies a material being? In Dissertation of 1770, Kant recovery the question about the relations that establishes between physical bodies and between bodies with a plausible unity of World found in a outside world being, or a common cause (unique): God. Those relations, in a sense, make reference to the psycho-physical commerce question established Dreams of a Spirit-Seer. In Critique of Pure Reason, in turn, the question is retaken in reason of Kantian criticism to traditional theories of Soul's pure doctrine, which are nothing beyond "paralogism of transcendental doctrine of soul, which is falsely understood as science of pure reason about the nature of thinking being" ( $\mathrm{KrV}, \mathrm{B} 403)$. In this sense, we will treat the question between the three works mentioned, seeking, at least, raise the question of communication possibility between the two worlds and, maybe, between one being and another one.

Keywords: Psycho-physical influx; Soul and body; Swedenborg. 
Na década de 1760 Kant escreve um ensaio intitulado Sonhos de um visionário explicados por sonhos da metafísica ${ }^{1}$ (TG), obra que tem como uma de suas teses a crítica ao racionalismo dogmático, com suas provas e pressupostos absurdos, sem comprovação que convença. Nesse sentido, Kant lança mão de Swedenborg, um visionário sueco, que afirma trocar contato com seres que residem em outro mundo, e consegue transpor para o campo da sensibilidade o que consegue ver no suposto mundo dos espíritos, o mundo suprassensível.

A figura de Swedenborg é importante para compreender a possibilidade de conhecer o mundo que transcende o conhecimento sensível. Ele, em suas viagens no mundo suprassensível, entra em contato com seres que outrora residiam na terra, e agora, no mundo espiritual continuam a trocar informações com seres terrenos, ao menos com aqueles que conseguem tal troca. Vale citar um fato em que Swedenborg confirma seu 'dom', transpondo o mundo sensível e atingindo o mundo suprassensível. Kant cita tal acontecimento em uma $\mathrm{Carta}^{2}(\mathrm{Br})$, do seguinte modo:

A senhora Marteville, viúva do embaixador da Holanda em Estocolmo, tempos depois da morte de seu marido, foi procurada por Croon, um joalheiro, a respeito de uma dívida do extinto com ele. A viúva não podia acreditar que seu marido, um homem de hábitos conservadores, pudesse ter deixado alguma dívida por saldar. Mas, por mais que procurasse, não conseguia encontrar o recibo correspondente. Como a quantia era bem alta, ela decidiu convidar Swedenborg à sua casa. Depois de pedir-lhe desculpas por importuná-lo. Pediulhe que, se realmente possuísse poderes paranormais, como se dizia, talvez pudesse perguntar ao seu marido onde tinha guardado o tal recibo. Swedenborg acedeu, prontamente, ao pedido. Daí a três dias, Swedenborg voltou à casa da senhora Marteville e, em tom calmo e pausado, contou-lhe que havia conversado com seu marido e este lhe dissera que a dívida em causa tinha sido paga, uns sete meses antes de sua morte e o recibo estava guardado num compartimento de sua escrivaninha. A viúva retrucou que a escrivaninha tinha sido totalmente revistada e o recibo não fora encontrado entre os documentos. Swedenborg, então, lhe disse que, ao se abrir a gaveta esquerda da escrivaninha até o fim, um fundo falso revelaria um compartimento secreto onde estavam guardados seus papéis pessoais e o tal recibo. Após ouvir atentamente as instruções de Swedenborg, a viúva e alguns dos presentes rumaram para a sala onde estava a escrivaninha. Lá chegando, abriram-na, conforme as instruções de Swedenborg e lá estavam os documentos pessoais do extinto e o recibo em questão. (Br, AA 10: 45-46).

\footnotetext{
${ }^{1}$ As obras de Kant, citadas neste artigo, serão abreviadas seguindo o Sistema de citação preparadas pela KantForschungsstelle der Johannes Gutenberg-Universität Mainz. As citações seguirão pela abreviatura de cada obra, listada na sequência, e entre parênteses depois do nome completo da obra em sua primeira referência. Sistema de citação: Siglum, AA (Bd.-Nr.): Seite[n]. Zeile[n] / AA Akademie-Ausgabe. Obras de Kant: Br: Briefe (AA 10-13); KrV: Kritik der reinen Vernunft (zu zitieren nach Originalpaginierung A/B) (AA 03 e 04); MSI: De mundi sensibilis atque intelligibilis forma et principiis (AA 02); Refl: Reflexion (AA 14-19); TG Träume eines Geistersehers, erläutert durch die Träume der Metaphysik (AA 02); V-MP-L 1 Kant Metaphysik L 1 (Pölitz) (AA 28).

${ }^{2}$ Carta a Charlotte von Knobloch, Königsberg 10 Aug. de 1763. Sobre o assunto ver: TROBRIDGE, G. L. Swedenborg, vida e ensinamentos. Rio de Janeiro: Sociedade Religiosa A Nova Jerusalém, 1998.
} 
Aqui, reside a questão principal da nossa abordagem, a troca de informações entre o sujeito e o mundo dos espíritos. Nos Sonhos de um visionário, Kant utiliza a definição clássica de espírito: um ser imaterial, simples, dotado de razão e que pode ocupar um ser material sem lhe causar a força da impenetrabilidade. É preciso compreender que Kant trata do conceito de espírito tendo por base uma crítica ao racionalismo que define o conceito de espírito sem, ao menos, comprovar ou demonstrar a sua existência.

Segundo Kant:

Só podereis manter, portanto, o conceito de um espírito, se pensardes em seres que poderiam estar presentes mesmo em um espaço cheio de matéria, portanto seres que não possuem em si a propriedade da impenetrabilidade e que nunca constituiriam um todo sólido, estejam reunidos no número que quiser. Seres simples desta espécie serão chamados seres imateriais e, se possuírem razão, espíritos. (TG, AA 02: 321).

Ao contrário, Kant continua e define o ser material:

Mas substâncias simples, cuja composição resulta em um todo impenetrável e extenso, serão chamadas unidades materiais, e seu todo, matéria. Ou o nome de um espírito é uma palavra sem qualquer sentido ou seu significado é o indicado. (TG, AA 02: 321).

É possível perceber que o espírito é definido como um ser imaterial, simples e dotado de razão, enquanto que o corpo é um ser material, simples, que pode ser um agregado de partes simples formando um composto. O corpo ligado a um ser imaterial (alma), que deve vivificá-lo, será um corpo dotado de razão, corpo e alma, uma vez que alma, assim como o espírito, é um ser imaterial. Além disso, é preciso compreender a propriedade da impenetrabilidade, pois corpo e alma são de espécies diferentes, mas o segundo ocupa o primeiro sem preenchê-lo.

Na Reflexão 4230 (Refl), Kant se indaga sobre a seguinte questão: como é possível a união do ser material com o ser imaterial? Essa questão se desenvolve dentro da questão da impenetrabilidade, em que um ser material não causa força repulsiva a um ser imaterial, já que eles são de naturezas diferentes. Nesse ponto, Kant retoma a argumentação escolástica de que a alma está esparramada pelo corpo, em que diziam: "minha alma está toda em todo corpo e toda em cada uma de suas partes" (TG, AA 02: 325, grifo do autor); do mesmo modo, Kant retoma Descartes, que afirma que a alma estaria localizada na glândula pineal, em algum lugar do cérebro. Nas palavras de Kant, dirigindo certa crítica aos sábios que assim pensam: "a alma do homem tem sua sede no cérebro e um lugar indescritivelmente pequeno nele é sua morada. Ali ela se sente como a aranha no centro de sua teia" (TG, AA 02: 325326). 
A questão da impenetrabilidade é uma questão que se configura no campo da força física e do movimento dos corpos dentro do âmbito do mecanicismo em relação ao choque entre corpos materiais, mas que pode se aplicar ao conceito de alma enquanto ser imaterial que ocupa um ser material, mesmo que o ser imaterial não possua tal propriedade. Tal questão mostra a possibilidade de uma comunicação entre corpo e alma, por ocuparem um mesmo espaço e estarem ligados um ao outro, mas esta comunicação permanece sem uma explicação palatável, e se complica ainda mais quando se conhece um sujeito que afirma ter contato com outros seres. Ou seja, será que Swedenborg é um ser imaterial? Ou simplesmente ele tem o âmago aberto e pode receber informações de outro mundo, tal como a comunicação "natural" que pode existir entre a alma e o espírito, uma vez que ambos são da mesma espécie e participam de um suposto mundo espiritual?

$\mathrm{Na}$ presença de Swedenborg, Kant aproxima as teses metafísicas junto às fantasias criadas por Swedenborg, apontando sua crítica ao racionalismo de cunho dogmático. No entanto, esse ilustre ser dos dois mundos proporciona uma investigação que leva em consideração a passagem de um mundo sensível para o mundo suprassensível. Assim, teríamos uma configuração da alma humana em contato com o corpo, juntamente com um contato com o outro mundo por meio de sua relação com o espírito. Ou seja, temos três entidades: o espírito, a alma e o corpo. Elas se caracterizam do seguinte modo: o espírito reside em um mundo fora do mundo terreno e mantém contato com a alma, que é da mesma espécie; a alma ocupa o corpo e mantém relação com o outro mundo, pois está ligada ao espírito; assim, a alma está entre o mundo sensível, ligada ao corpo, e mundo suprassensível, ligada ao espírito. É nesse sentido que se pode falar de uma possibilidade de comunicação entre dois mundos, pressupondo uma comunidade de seres espirituais em comunicação com a alma.

Nos Sonhos de um visionário, Kant afirma que, diante das visões de Swedenborg, há que se pressupor que a alma possui um contato com o outro mundo, do seguinte modo: a alma unida ao corpo conhece os objetos da sensibilidade; o espírito em sua relação com a alma também busca conhecer tais objetos, mas não consegue, uma vez que ele não está atrelado ao corpo, permanecendo num mundo dos espíritos. Desse modo, deve-se pressupor que a alma vê pelos olhos do corpo enquanto atrelada a ele, mas desprendida do corpo, nada vê, e também se esquece do que viu, quando adentra ao mundo dos espíritos ${ }^{3}$. Há, portanto, uma

\footnotetext{
${ }^{3}$ É possível aproximar essa argumentação com os argumentos de Platão no Diálogo Fédon, onde ele afirma que a alma humana possui ligação com o Mundo Inteligível (ou Mundo das Ideias) quando não atrelada ao corpo, permanecendo em contato com as Formas (Ideias puras). Ao passo que, atrelada ao corpo, a alma esquece o que
} 
alma ligada ao corpo, mas também ligada ao espírito, enquanto ser dotado de razão existente em outro mundo. Alma e espírito são, nesse sentido, diferentes.

Considerando que há um espírito, uma alma, um corpo e Swedenborg, que como alma e corpo tem acesso ao outro mundo, é possível afirmar a existência de uma troca de informações entre um mundo visível e invisível, mesmo que isso possa ser dito como impossível ou meramente fantasia. Aqui, Swedenborg é configurado como o "oráculo dos espíritos" (TG, AA 02: 362), que possui sua alma aberta para receber informações, o que o torna diferente dos outros homens. Se há uma alma que se comunica com o outro mundo, por meio de sua ligação com o espírito, há, portanto, um mundo espiritual. Se o mundo espiritual existe, as almas podem se comunicar entre si por telepatia, mas não é o que ocorre.

Desse modo, no contexto dos Sonhos, há um argumento que pode ser configurado como um dos principais pontos para compreender os limites do conhecimento através das relações entre a alma humana e o suposto mundo dos espíritos. Tal argumento diz respeito ao comércio psico-físico (troca de informações) entre o mundo dos espíritos e o mundo sensível por intermédio da alma que se encontra no corpo do homem. Assim, o mundo espiritual teria um contato direto com o mundo sensível e vice-versa. Além disso, se o mundo dos espíritos existisse de fato, seria muito natural que todos os seres dotados de alma tivessem acesso a ele. O mesmo contato da alma humana com o mundo dos espíritos permitiria, como já adiantamos, um contato telepático entre os seres racionais, uma vez ligados com o mundo espiritual através da alma. Vale notar que, nas Preleções de Metafísica Pölitz (V-MP-L 1, AA 28: 188), a alma é tratada não somente como a alma do homem, como alma inteligente, mas também como estando em 'contato' com o corpo. Mas ela não está somente em contato com o corpo, ela está também em comunidade, pois é possível estar em contato com outros corpos, como entre nós (eu e você), mas isso não é comunidade. A comunidade é o contato (a relação), onde a alma e o corpo produzem uma unidade, onde as alterações do corpo são ao mesmo tempo as mesmas alterações da alma e vice-versa. Ou seja, no ânimo não ocorre nenhuma alteração que não seja a alteração que corresponde à alteração do corpo.

Na Crítica da razão pura (KrV), Kant aponta uma breve definição da alma como uma substância simples, una e existente, que mantém relações com objetos possíveis encontrados no espaço e os conceitos de sua doutrina teriam origem na composição desses quatro elementos: substância, simplicidade, unidade e relação (com objetos no espaço). Tal definição

outrora conhecia junto às Formas, mas ao se deparar com as coisas do Mundo Sensível através dos 'olhos do corpo', relembra o que antes contemplou no Mundo das Ideias, e por rememoração (reminiscência), obtém o conhecimento e reconhecimento do que está agora em contato: os objetos do mundo sensível. 
aponta a crítica de Kant às teorias tradicionais da doutrina pura da alma, semelhante ao que Kant procurou mostrar nos Sonhos.

Desses elementos originam-se, unicamente pela composição, todos os conceitos da doutrina pura da alma, sem reconhecer minimamente um outro princípio. Esta substância, simplesmente como objeto do sentido interno, fornece o conceito de imaterialidade; como substância simples, o conceito de incorruptibilidade; a sua identidade como substância intelectual fornece a personalidade; todos esses três elementos em conjunto, a espiritualidade; a relação com os objetos no espaço fornece o commercium com os corpos. Por conseguinte, esta substância representa a substância pensante como o princípio da vida na matéria, isto é, como alma (anima) e como o fundamento da animalidade; esta, limitada pela espiritualidade, fornece a imortalidade. (KrV, B 403, grifo do autor).

Pode-se perceber que a alma é imaterial (sentido interno), incorruptível (simples) e substância intelectual (identidade) - personalidade - tais elementos concebem sua espiritualidade. Com respeito à relação da alma com objetos no espaço, vê-se o comércio psico-físico entre alma e corpos, ou seja, a alma por um lado é o princípio da vida, a animalidade; por outro, ela poderia se comunicar com outras almas mediante um mundo comum de espíritos, tal como Kant esboçou nos Sonhos.

Retomando os argumentos dos Sonhos, a alma humana, que vivifica o corpo, deve estar ligada a dois mundos: sensível e espiritual. Ela enquanto ligada ao corpo sente o mundo imaterial; no entanto, ela transmite influências de um suposto mundo imaterial, pois, está ligada também ao espírito. Ou seja, a alma é uma espécie de meio-termo entre o mundo sensível e o mundo espiritual. Nesse ponto, deve-se compreender que a alma é distinta do espírito, à medida que o espírito pertence a outro mundo que não é sensível. Através da alma, entretanto, busca conhecer tal mundo.

Com efeito, a alma, ligada ao espírito, concebe vida ao corpo contemplando por meio dele o mundo sensível; se desligada do corpo, passa a viver na comunidade espiritual, pois a ela está ligada. Porém, não carrega consigo o que outrora tinha por representação, o mundo material (sensível).

De acordo com isso, é certamente um mesmo sujeito que pertence como um membro simultaneamente ao mundo visível e invisível, mas não exatamente a mesma pessoa, porque as representações de uma não são ideias que acompanhem as representações do outro mundo, devido a sua constituição distinta, e, por isso, não lembro enquanto homem aquilo que penso como espírito e, vice-versa, meu estado como um homem não entra na representação de mim mesmo como um espírito. (TG, AA 02: 337-338).

A suposição da existência de um mundo espiritual, de seres imateriais, deve ser pressuposta à medida que a matéria morta do mundo deve ser vivificada por algo distinto do 
corpo material; ou seja, por algo imaterial que não participa da força de impenetrabilidade e possa ocupar o corpo que não imprime resistência à sua presença.

Nesse sentido, se há ou não seres imateriais que vivifiquem a matéria morta, tais seres estariam em uma comunidade de seres imateriais em relações recíprocas e, possivelmente, em relações com os corpos materiais por intermédio da alma. Haveria, portanto, uma espécie de comércio psico-físico, uma relação da alma com a comunidade dos espíritos.

[...] que a alma humana se encontra também nesta vida em uma comunidade indissolúvel com todas as naturezas imateriais do mundo dos espíritos, que ela tanto age sobre essas quanto recebe delas influências, das quais não tem, contudo, consciência como homem, enquanto tudo está bem. Por outro lado, é também provável que as naturezas espirituais não possam ter imediata e conscientemente impressão sensível do mundo corporal, porque não estão ligadas com nenhuma parte da matéria em uma pessoa, para por meio disso tornarem-se conscientes de seu lugar no mundo material e, através de órgãos artificiais, da relação dos seres extensos seja consigo mesmos seja uns com os outros, mas que elas podem influenciar certamente as almas dos homens como seres de natureza idêntica e se encontram de fato sempre em comunidade recíproca com elas, só que de tal modo que, na comunicação das representações, aquelas que a alma contém em si como um ser dependente do mundo corporal não podem passar para outros seres espirituais e os conceitos dos últimos, como representações intuitivas de coisas imateriais, não podem ser apreendidos claramente pela consciência do homem, pelo menos não em sua constituição própria, porque os materiais para ambos os tipos de ideia são de espécie distinta. (TG, AA 02: 333).

Diante disso, se tal 'comércio' fosse possível e se a alma humana participasse dele, seria também possível que todos os seres racionais se comunicassem entre si, como por telepatia - o que não é o caso.

Essas argumentações presentes nos Sonhos desembocam na Dissertação de $1770^{4}$ (MSI), dentro de um contexto que se aproxima do suposto comércio psico-físico, mas, guardadas as devidas proporções, neste último escrito as relações se estabelecem entre corpos físicos e entre tais corpos e uma possível unidade do Mundo encontrada em um ser fora do mundo, ou uma causa comum (única): Deus.

Surge então a questão: “[...] como é possível que várias substâncias estejam em mútuo comércio e, por esta razão, pertençam ao mesmo todo a que se chama mundo"? (MSI, AA 02: 407, grifo do autor). Tal questão se origina em outra: “em que princípio se funda esta mesma relação de todas as substâncias, a qual, considerada intuitivamente, se chama espaço"?

\footnotetext{
${ }^{4}$ Aqui, Kant (MSI, AA 02: 409) compreende dois tipos de comércio: real e físico, e ideal e por simpatia. Pelo primeiro, o mundo é um todo real (por influência física); pelo segundo, o mundo é um todo ideal (por simpatia). Dada a existência das coisas no mundo mediante conexão com um princípio comum (causa comum) tem-se uma harmonia geralmente estabelecida; ao contrário, a relação entre substâncias, em que há adaptação dos estados individuais de cada substância com outro, tem-se a harmonia singularmente estabelecida. No primeiro caso há, portanto, um comércio real e físico; no segundo, um comércio ideal e por simpatia.
} 
(MSI, AA 02: 407). Estas duas questões procuram mostrar duas coisas: 1) a existência dos objetos se dá no espaço e tempo, campo sensível onde se dá a relação (comércio) entre corpos físicos; 2) o mundo como forma gera a questão acerca da totalidade e conexão de todas as substâncias, uma unidade: Deus.

Sendo dadas várias substâncias, o princípio do comércio possível entre elas não consiste na mera existência das mesmas, mas requer-se além disso algo a mais a partir do qual sejam compreendidas as relações mútuas. Com efeito, para subsistirem elas não necessitam de se relacionar com algum outro, a não ser porventura com a sua causa; porém, a relação do efeito à causa não é um comércio, mas uma dependência. Por conseguinte, se ocorre algum comércio de umas substâncias com outras, há a necessidade de uma razão especial que o determine com precisão. (MSI, AA 02: 407, grifo do autor).

Para compreender as relações é preciso algo 'a mais' do que a própria existência das coisas, e se há um comércio entre substâncias, é necessário uma razão para determinar tal comércio $^{5}$. Nesse sentido, uma razão que determine todas as relações e também conceda unidade deve ser única, pois, se há um mundo, deve existir uma única causa. Caso contrário, se há várias causas para determinar a unidade do mundo existirão, portanto, vários mundos o que não é o caso. Assim, tudo deve ser sustentado pela força infinita de um só:

“[...] a mente humana não é afetada pelas coisas externas e o mundo não se oferece ilimitadamente ao seu olhar senão na medida em que ela mesma é sustentada com todas as outras pela mesma força infinita de um só" (MSI, AA 02: 409, grifo do autor).

De modo semelhante, nas Preleções de Metafísica Pölitz (V-MP-L 1, AA 28: 112), onde existe um comércio há não só um influxo, mas também um influxo mútuo. No entanto, tal relação deve ser sustentada por um único ser, que garante a unidade do todo diante da variedade da substância que deve ser configurada numa unidade. Pois, se há um mundo, deve existir uma causa única que sustente as relações existentes nele, já que se existissem outras causas, existiriam outros mundos - o que não é o caso.

Com efeito, a suposição da existência de um mundo espiritual (Sonhos) ou um mundo inteligível (Dissertação de 1770), ou uma comunidade dos espíritos que mantenha relação com o mundo dos seres racionais vivificados por meio da alma, ou ainda um Deus que mantenha a unidade das relações entre as substâncias e entre uma causa única dessas relações, leva a crer o seguinte: há, de fato, uma divisão entre mundo sensível e mundo inteligível e deve-se supor uma relação entre eles; há, de fato, um conhecimento do mundo sensível e a suposição de poder, ao menos, pensar um mundo inteligível; há, de fato, o conhecimento dos

\footnotetext{
${ }^{5}$ É possível dizer que a citação acima é, de certo modo, "parafraseada" nas Preleções de Metafísica Pölitz (VMP-L 1, AA 28: 110-111), que assegura a afirmação da existência do comércio e a existência de uma causa única que determine as relações e conceda a unidade requerida.
} 
fenômenos e a suposição da existência de uma coisa em si mesma expressa pela aparição dos fenômenos.

Nesse sentido, Kant aponta a possível sistematicidade do mundo dos espíritos como real ou simplesmente hipotética:

Seria uma beleza se uma tal constituição sistemática do mundo dos espíritos, como a representamos, pudesse ser deduzida ou mesmo só inferida com a probabilidade de alguma observação qualquer efetiva e geralmente admitida, e não apenas do conceito da natureza espiritual em geral, demasiadamente hipotético. (TG, AA 02: 333).

Como se vê, é possível afirmar a existência do espírito, como um conceito, inferido de modo racional, ao mesmo tempo em que é possível inferir a existência de um mundo dos espíritos ou uma comunidade dos espíritos, 'hipostasiando' sua sistematicidade. Ou seja, há hipóteses e pressupostos sobre a existência do espírito ou da comunidade de espíritos, assim como podemos inferir a existência de um ser supremo que ordena o mundo, mas que não podemos conhecê-lo e provar, de fato, sua existência (ao menos em vida). Desse modo, o que se pode mostrar é que se existe uma comunicação entre a alma e o suposto mundo dos espíritos, sua comprovação pode somente ser dada em sentido negativo: pode-se pressupor que existe um mundo dos espíritos, mas não é possível provar tal existência. Do mesmo modo: é possível que exista uma troca de informações entre a alma (atrelada ao corpo) e o espírito residente no mundo suprassensível, mas não é possível constatar tal possibilidade enquanto seres de um mundo sensível, ao menos se fossemos como Swedenborg, se e somente se as histórias deste ilustre ser, como oráculo dos espíritos, for verdadeira.

No mesmo sentido, se há ou não uma comunicação de nossa alma com um mundo extracorpóreo, e se podemos acreditar nisso ou duvidar de tal possibilidade, é preciso recorrer à corrente espiritualista, juntamente com seus adeptos, a fim de que comprove que nossa alma, atrelada ao nosso corpo, possui uma ligação íntima com espíritos fora de corpos materiais, sendo possível, portanto, a comunicação. Pois somente é possível uma comunicação entre alma e espírito se os mesmos são dotados da mesma característica, qual seja, a imaterialidade.

Somente há comunicação se a alma se abre ao espírito, e somente existe uma alma atrelada ao corpo, pois desatrelada das amarras do corpo, ela não seria mais alma, e sim espírito. Ou seja, alma e espírito são seres imateriais e ocupam lugares diferentes. O primeiro, ocupa o corpo e o vivifica; o segundo, ocupa um mundo que não conhecemos em vida, e vive em comunidade com outros seres de mesma espécie. Com isso, a alma poderia ter contato 
com o outro mundo por intermédio do espírito e este pode ter acesso a informações do mundo real, sensível, visível, em contato com a alma.

Mesmo assim, continuamos na pressuposição da existência de um mundo espiritual, sem provar, de fato, sua veracidade ou existência, e permanecemos na dúvida e continuamos também na crença da espiritualidade comunicável entre um ser dotado de corpo e alma e um ser espiritual (imaterial).

Kant, se vivesse em nossos dias, se alegraria, talvez, em encontrar outros adeptos das doutrinas de Swedenborg, que endossariam as histórias fantasiosas ou as crenças em seres de outro mundo. Ao menos, Kant comprovaria que há outros crentes e postularia, mais uma vez, a ponte entre o nosso mundo real e o mundo invisível, corroborando sua tese hipotética acerca da existência de um mundo espiritual.

\section{Referências}

KANT, Immanuel. Kants Gesammelte Schriften. 29 Band. Berlin: Georg Reimer, 1902. . Crítica da razão pura. 2. ed. São Paulo: Abril Cultural, 1983. (Coleção Os Pensadores, Kant I). . Crítica da razão pura. 5. ed. Lisboa: Fundação Calouste Gulbenkian, 2001. Acerca da forma e dos princípios do mundo sensível e inteligível. In: SANTOS, L. R. dos.; MARQUES, A. Dissertação de 1770 seguida de Carta a Marcus Herz. 2. ed. Lisboa: Casa da Moeda, 2004. p. 23-105 Sonhos de um visionário explicados por sonhos da metafísica. In: Escritos pré-críticos. São Paulo: Ed. Unesp, 2005. p. 141-218. TROBRIDGE, George. L. Swedenborg, vida e ensinamentos. Rio de Janeiro: Sociedade Religiosa A Nova Jerusalém, 1998. 